\title{
Overview of C-ITS Deployment Projects in Europe and USA
}

\author{
Areti Kotsi ${ }^{1}$, Evangelos Mitsakis ${ }^{1}$, Dimitris Tzanis ${ }^{1}$ \\ ${ }^{1}$ Centre for Research \& Technology - Hellas (CERTH) - Hellenic Institute of Transport (HIT) \\ E-mail: akotsi@certh.gr, emit@certh.gr, dtzanis@certh.gr
}

\begin{abstract}
Cooperative Intelligent Transportation Systems (C-ITS) are technologies that enable vehicles to communicate with each other and with the road infrastructure. These innovative technologies enable road users and traffic managers to share useful information, assisting the coordination of their actions. During the last years various initiatives providing policy rules for C-ITS deployment and a large number of projects demonstrating C-ITS implementation have taken place in Europe and USA. However, the identification of the status of C-ITS deployment remains ambiguous at binational level. The purpose of this paper is to provide an overview of the European and US milestones, that have been reached so far in the field of C-ITS, by identifying and reporting the policy framework, as well as the projects concerning C-ITS deployment in Europe and USA.
\end{abstract}

Keywords: Cooperative Intelligent Transportation Systems, large-scale deployments, innovation, projects.

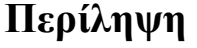

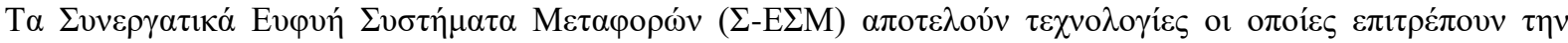

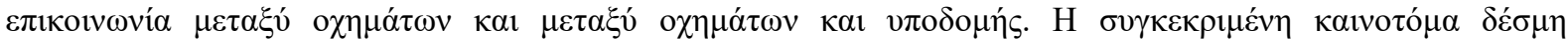

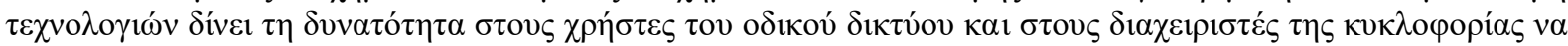

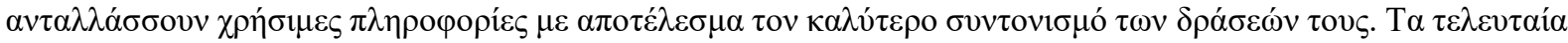

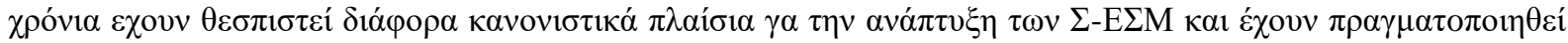

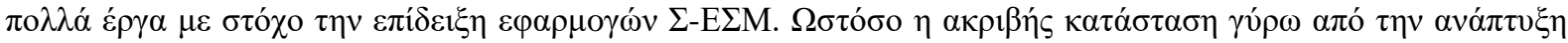

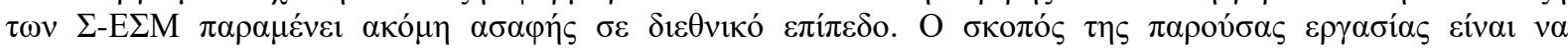

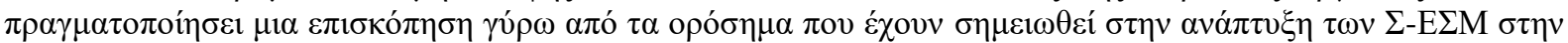

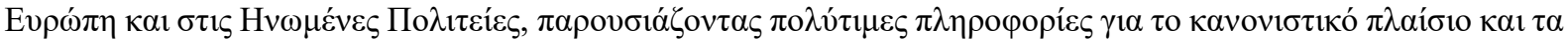

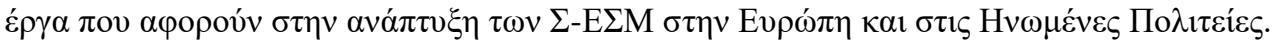

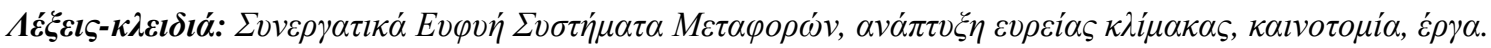

\section{Introduction}

The technological progress of the last decade led to the expansion of transportation research especially in the field of Cooperative Intelligent Transportation Systems (C-ITS). This paper aims to provide the reader with information about the status of the deployment of C-ITS in Europe and USA. The reader is first introduced to European and US policies concerning C-ITS, while a detailed presentation of C-ITS deployment projects in Europe and USA constitutes the main part of this paper. 
The European C-ITS policy initiatives referring to the timeframe of 2010-2017 are: the Directive 2010/40/EU (European Commission, 2010), the 2011 White Paper "Roadmap to a Single European Transport Area - Towards a competitive and resource efficient transport system" (European Commission, 2011), the "Roadmap between automotive industry and infrastructure organisations on initial deployment of Cooperative ITS in Europe" (Amsterdam Group, 2013), the list of "Day 1 applications" (European Commission, 2016a), the "AG White Papers" (Amsterdam Group), the document "C-ITS Platform - Final Report - January 2016 (Phase 1)" (C-ITS Platform, 2016), the Roadmap "A Master Plan for the deployment of Interoperable Cooperative Intelligent Transport Systems in the EU" (C-ITS Master Plan) (European Commission 2016b), the "Declaration of Amsterdam - Cooperation in the field of connected and automated driving on connected and automated driving" (European Commission 2016c), and the "C-ITS Certificate Policy for deployment and operation of European C-ITS" (European Commission, 2017a).

US C-ITS policy initiatives covering the time period between 1996-2017 comprise of: the "National ITS Architecture" (US Department of Transportation, 2019a), the "Turbo Architecture" (US Department of Transportation, 2019b), the standards for CV deployment by the US Department of Transportation Intelligent Transportation Systems Joint Program Office (USDOT ITS JPO), the agreement "EU - U.S. Joint Declaration of Intent on Research Cooperation in Cooperative Systems" (Stančič Z., Appel. P. H., 2009), the guideline "2015 FHWA Vehicle to Infrastructure Deployment Guidance and Products" (US Department of Transportation, 2014), the system architecture framework "Connected Vehicle Reference Implementation Architecture" (CVRIA) (US Department of Transportation, 2017a), the "Architecture Reference for Cooperative and Intelligent Transportation" (ARC-IT) (US Department of Transportation, 2017b), and two tools, "Regional Architecture Development for Intelligent Transportation" (RAD-IT) (US Department of Transportation, 2017c) and "Systems Engineering Tool for Intelligent Transportation" (SET-IT) (US Department of Transportation, 2017d).

\section{Large-scale deployment projects in Europe and USA}

\subsection{European activities}

The European Commission (EC) launched under the Sixth Framework Programme (FP6) (2002-2006) the projects SAFESPOT (European Commission, 2007), COOPERS (European Commission, 2008) and CVIS (European Commission 2016d), all focusing on the provisions of real-time safety related traffic/ infrastructure information for drivers. The following funding programme, 7th Framework Programme for Research and Technological Development (FP7) (2007-2013), provided the budget for a series of research and innovation initiatives, including the projects: SAFERIDER (European Commission, 2017b), euroFOT (European Commission, 2017c), SISCOGA (FOT-NET DATA), PRESERVE (European Commission, 2017d), COMeSafety2 (European Commission, 2017e), FOTsis (European Commission, 2017f), ITSSv6 (European Commission, 2017g), MOBiNET (European Commission, 2017h), P4ITS (European Commission, 2017i), VRUITS (European Commission, 2014a), COMPANION (European Commission, 2014b), HeERO2 (European Commission, 2017j), TeleFOT 
(European Commission, 2017k), DRIVE C2X (European Commission, 2014c), eCoMove (European Commission, 20171), interactIVe (European Commission, 2017m), and OVERSEE (European Commission, 2017n). The objectives of the projects covered various aspects concerning cooperative systems, such as the provision of Advanced driver-assistance systems (ADAS) and In-vehicle infotainment (IVI) systems, the assessment of C-ITS through Field Operational Tests (FOTs) in various places in Europe, the provision of security and privacy subsystems for Vehicle-to-Everything (V2X) communication systems, the development of open platforms for Europe-wide mobility services, as well as the development of architectures for C-ITS services.

During the same period (2007-2013), the Competitiveness and Innovation Framework Programme (CIP) funded five projects. The FREILOT project aimed to increase energy efficiency in road goods transport through C-ITS services (European Commission, 2017o), while the COSMO project demonstrated the energy efficiency-related benefits of integrating advanced cooperative traffic management systems (European Commission, 2017p). The HeERO project prepared the deployment of the necessary infrastructure in Europe for the "PanEuropean in-vehicle emergency call service, eCall" (European Commission, 2017q).

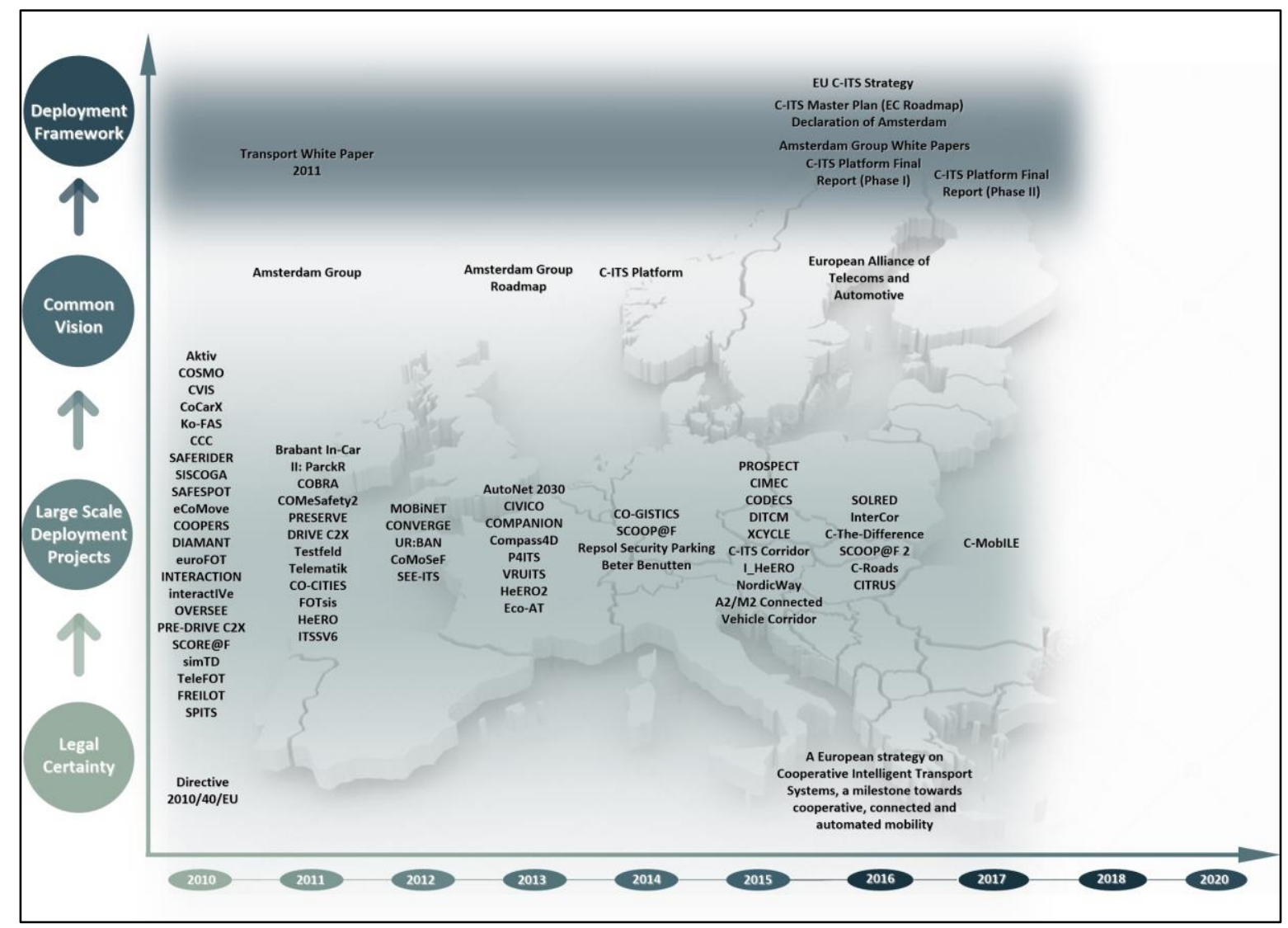

Figure 1: C-ITS European activities overview 
Through the Compass4D, three cooperative services (Road Hazard Warning, Red Light Violation Warning and Energy Efficient Intersection service) were implemented in seven European cities (Bordeaux, Copenhagen, Eindhoven-Helmond, Newcastle, Thessaloniki, Verona and Vigo) (European Commission, 2017r). The CO-GISTICS project aimed to implement C-ITS services, which would increase energy efficiency and equivalent $\mathrm{CO}_{2}$ emissions, in seven European cities/ logistics hubs (Bordeaux, Frankfurt, Thessaloniki, Trieste, Arad, Bilbao and Vigo) (European Commission, 2017r).

The EU funding instrument Connecting Europe Facility (CEF) (2014-2020) supported a significant number of C-ITS activities, including the projects SCOOP@F (European Commission, 2015), Repsol Security Parking (European Commission, 2018a), I_HeERO (European Commission, 2018b), NordicWay (European Commission, 2018c), CITRUS (European Commission, 2009), SolC-ITS (European Commission, 2018d), InterCor (European Commission, 2018e), and C-Roads (C-ROADS). The focus of the projects is mainly on the establishment of a harmonized strategic rollout and common specifications on C-ITS implementation among EU members, aiming in the promotion of wide-scale C-ITS deployment in Europe. Under the EU Research and Innovation programme Horizon 2020 (2014-2020), the following projects were launched: PROSPECT (European Commission, 2017t), CIMEC (European Commission, 2017u), CODECS (European Commission, 2017v), XCYCLE (European Commission, 2017w) and C-MobILE (European Commission, 2018f). Fields covered under the framework of these projects comprise of the support of strategic and technical policy solutions and processes for a consolidated C-ITS rollout, as well as the deployment of C-ITS services in urban environments, with the scope of establishing a fully safe and efficient road transport for Vulnerable Road Users (VRUs).

A list of projects funded under the funding programmes ICT Policy Support Programme (ICT PSP), ERA-NET, South East Europe Transnational Cooperation Programme, Celtic-Plus, European Regional Development Fund (ERDF), and EC DG MOVE are respectively: the COBRA project (Vermaat P., Hopkin J., van Wees K. A. P. C., Faber F., Deix S., Nitsche P., and Michael. K., 2012), the SEE-ITS project (Mitsakis E., Iordanopoulos P., Aifadopoulou G., Tyrinopoulos Y., and Chatziathanasiou M., 2012), the CoMoSeF project (Celtic-Plus Smart Connected World), and the project C-The Difference (Blervaque V., 2016). At national level, Germany introduced the projects CoCarX (Cooperative Cars eXtended - CoCarX, 2011), simTD (FOT_NET DATA), Ko-FAS (European Commission, 2018h), and UR:BAN (UR:BAN Urbaner Raum: Benutzergerechte Assistenzsysteme und Netzmanagement), focusing on Carto-Car (C2C) and Car-to-Infrastructure (C2I) communication for future C-ITS applications. The Netherlands launched the projects SPITS (FOT-NET DATA), Brabant In-Car II: ParckR (FOT-NET DATA), Beter Benutten (Optimising Use) programme (Ministry of Infrastructure and the Environment, 2017) and DITCM (DITCM Innovations, 2017). Austria through the Testfeld Telematik project, aimed for "developing, operating and demonstrating C-ITS services and systems within the framework of a test field in the greater Vienna area" (Eco-AT The Austrian contribution to the Cooperative ITS Corridor), while the ECo-AT project intended to "create harmonized and standardized C-ITS applications jointly with partners in Germany and the Netherlands" (Eco-AT The Austrian contribution to the Cooperative ITS Corridor). The French FOT, titled SCORE@F, implemented ITS stations, which used a standardized communication architecture (ITS Station Reference Architecture) (FOT-NET DATA), while 
UK launched the A2/ M2 (London to Dover) Connected Vehicle Corridor project, in order to create a living laboratory for C-ITS technologies (Department of Transport, 2016). At international level, German, Dutch and Austrian road operators set the basis for "a Europeanwide C-ITS implementation" under the Cooperative ITS Corridor project. The corridor Rotterdam-Frankfurt/M.-Vienna includes the implementation of two C-ITS services, Road Works Warning and Vehicle Data for improved traffic management (Cooperative ITS Corridor Joint deployment).

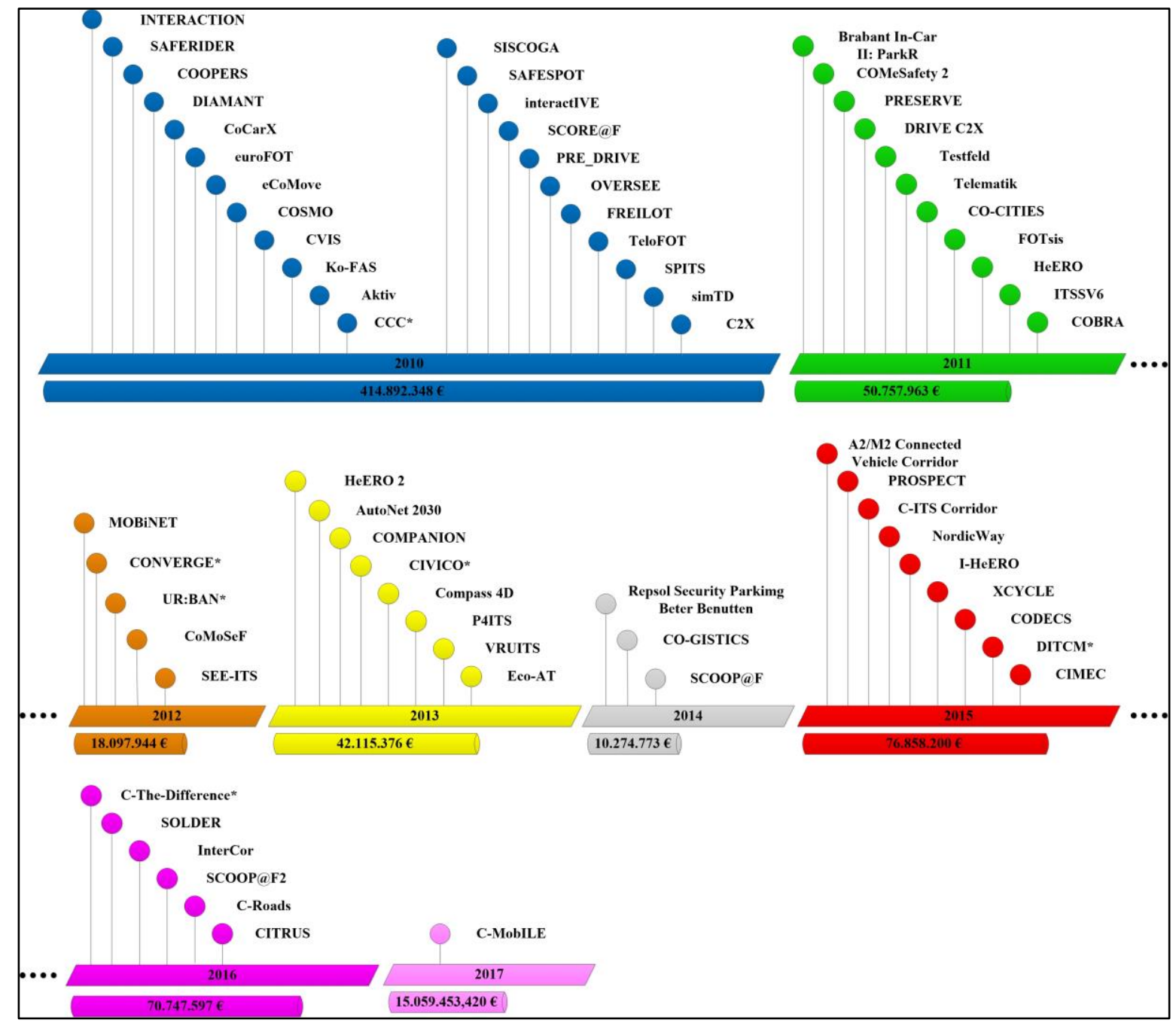

Figure 2: Large-scale deployment projects in Europe

\subsection{USA activities}

In 2008, the Arizona Transportation Research Center, the Arizona State University, the Maricopa County DOT and the Michigan DOT funded the pilot project "Arizona Emergency Vehicle Infrastructure Integration (E-VII)". The project consisted of two phases: Phase 1, 
including the analysis and deployment of prototype applications, and Phase 2, including the demonstration of applications, equipment interfaces and driver interaction with the on-board systems in a "parking lot" site at the Maricopa County. The scope was the development and testing of advanced technologies for emergency vehicles, providing better response to traffic incidents (Saleem F., and Nodes. S., 2008). In 2009, the Michigan DOT, the University of Michigan Transportation Research Institute (UMTRI) and the Institute for Information Industry launched the "Multipath Signal Phase and Timing (SpaT) Broadcast project". The aim of the project was the provision of speed advice to drivers, in order to pass safely through the green phase of the following signalized intersection. Moreover, SPaT provided drivers with a down counter, demonstrating via the vehicle's interface the remaining seconds of the green phase (Robinson R., and Dion F.).

In 2011 UMTRI in cooperation with USDOT, introduced the "Connected Vehicle Safety Pilot Model Deployment (SPMD)" project. The project included the collection of real-time data, in order to evaluate the effectiveness of Connected Vehicles (CV) safety technologies. Over 2800 volunteer vehicles from Ann Arbor were equipped with Vehicle-to-Vehicle (V2V) and Infrastructure-to-Vehicle (I2V) communication devices, in order to exchange Basic Safety Messages (BSMs) about speed, location and direction in a 73 lane-miles equipped roadway (US Department of Transportation, 2018a). In the same year, USDOT, Michigan DOT and the Federal Highway Administration (FHWA) sponsored the "Integrated Mobile Observations 2.0 (IMO)" project. The project implemented a system acquiring weather-road data from the I-94 corridor users (fleet of 60 vehicles) and providing it to weather analysts. The implemented system, an Android-based customized smartphone device (DataProbe), collected all the vehicle data, then transferring it to an UMTRI server for validation, storage and analysis (Belzowski B. M., and Cook. S. J.).

FHWA and Auburn University sponsored the "Heavy Truck Cooperative Adaptive Cruise Control" project, addressing the implementation of the Driver Assistive Truck Platooning (DATP), a form of Cooperative Adaptive Cruise Control (CACC) for heavy trucks. The equipment included radars, dedicated short-range communications (DSRC) based on V2V communications and satellite positioning technologies (Dr. Bevly D., Dr. Murray C., Dr. Lim A., Dr. Turochy R., Dr. Sesek R., Smith S., Apperson G., Woodruff J., Gao S., Gordon M., Smith N., Watts A., Dr. Batterson J., Bishop R., Murray D., Torrey F., Korn A., Dr. Switkes J., and Boyd S., 2015). In 2015 the University of Washington sponsored and coordinated the "Enhancing Safe Traffic Operations using Connected Vehicles Data" project. The project developed a cost-effective Communication Note $(\mathrm{CN})$ device and a mobile application (Android based), in order to advise drivers about hazardous scenarios and to warn VRUs (Li Z., 2016). Expanding the SPMD project, UMTRI and its partners launched the "Ann Arbor Connected Vehicle Test Environment" project, aiming to broaden the existing infrastructure to the entire 27-square miles of the City of Ann Arbor, and to include additional equipped vehicles (5000 until 2018) (UMTRI).

In an effort of expanding CV technology, USDOT launched the "Connected Vehicle Pilot Deployment Program". The main objective of the program was the innovative and costeffective combination of $\mathrm{CV}$ technologies and mobile applications, targeting in traveler mobility and safety increase, and environmental impacts reduction. The first phase of the 
program, completed in September 2016, included "a concept of operations, system requirements, safety plan, benefits evaluation plan, security management plan and development plan". The second phase, lasting 20 months, embodies "the detailed design, field equipment development and procurement, software development, integration and the installation of the invehicle devices and the roadside infrastructure". During the last phase, applications will be active and provided to drivers in New York City (NYC), Tampa (Florida) and Wyoming (US Department of Transportation, 2018b).

The NYC pilot includes three corridors: Manhattan Grid, Manhattan FDR Drive and Brooklyn Flatbush Avenue. The implemented applications focus on safety, promoting NYC's Vision Zero program. The implemented safety applications are based on V2V, I2V and Infrastructureto-Pedestrian (IVP) communications, covering 300 Road Side Units (RSUs) in the 3 corridors and $8000 \mathrm{CV}$ (US Department of Transportation, 2018c). Tampa pilot focuses on the deployment of $\mathrm{V} 2 \mathrm{~V}$ and $\mathrm{I} 2 \mathrm{~V}$ applications, in order to reduce congestion and collisions. Additionally, the pilot aims to "enhance pedestrian safety, speed bus operations and reduce conflicts between street cars, pedestrians and passenger cars at locations with high volumes of mixed traffic" using CV technology. Participants of the pilot deployment comprise of 1600 cars, 10 buses, 10 trolleys, 500 pedestrians, and 40 RSUs (US Department of Transportation, 2018d). The pilot site of Wyoming is a major freight corridor, assisting in the movement of goods across U.S.A. The pilot targets in safety improvement and reduction of "incident-related delays" via the following V2V and I2V applications: Forward Collision Warning (FCW) and Distress Notification. 400 vehicles (150 heavy trucks, 100 fleet vehicles, snowplows and highway patrol vehicles), equipped with On-Board Units (OBUs), as well as 75 RSUs will support operations (US Department of Transportation, 2018e).

In December 2015, USDOT introduced a project called "Smart City Challenge". The purpose of the project was the development of ideas, from mid-sized American cities, in order to establish a new and smart transportation system (US Department of Transportation, 2018f). City of Columbus won the challenge, trying now to revolutionize its transportation system through the "Columbus Smart City demonstration" project. The project includes CV deployment, upgrade of infrastructure and the development of an integrated data platform. Columbus DOT focuses on improving safety, mobility and environmental sustainability via the following CV applications: Transit Signal Priority, Freight Signal Priority, Eco-Approach and Departure at Signalized Intersections, Forward Collision Warning, Emergency Vehicle Preemption, Red Light Warning Violation, Speed Warnings at School Zones, Vehicle Turning Right in Front of Transit Vehicle, and Emergency Electronic Brake Light Warning. 400 city vehicles, 50 trucks, 100 school buses, 350 buses, and 2100 private light vehicles, equipped with DSRC units, as well as 175 intersections, equipped with RSUs, comprise the components of the implementation (US Department of Transportation, 2018g).

In 2016 the Federal Tiger Grant supported the TPIMS project, "Truck Park Information Management Systems". The goal of this project was the provision of real-time information to truck drivers, in order to assist in right and economical parking decisions (Mid America Association of State Transportation Officials, 2016). Within the Ohio Smart Mobility Corridor project, the US Route 33 was equipped with fiber optic cables, enabling researchers and traffic monitors to have a real-time connection with road wireless sensors (Smart Mobility Corridor). 
In 2017 the "5.9 GHz Dedicated short-range communication Vehicle-based Road and Weather Condition Application" project was launched, aiming to obtain road-weather information (US Department of Transportation, 2018h).

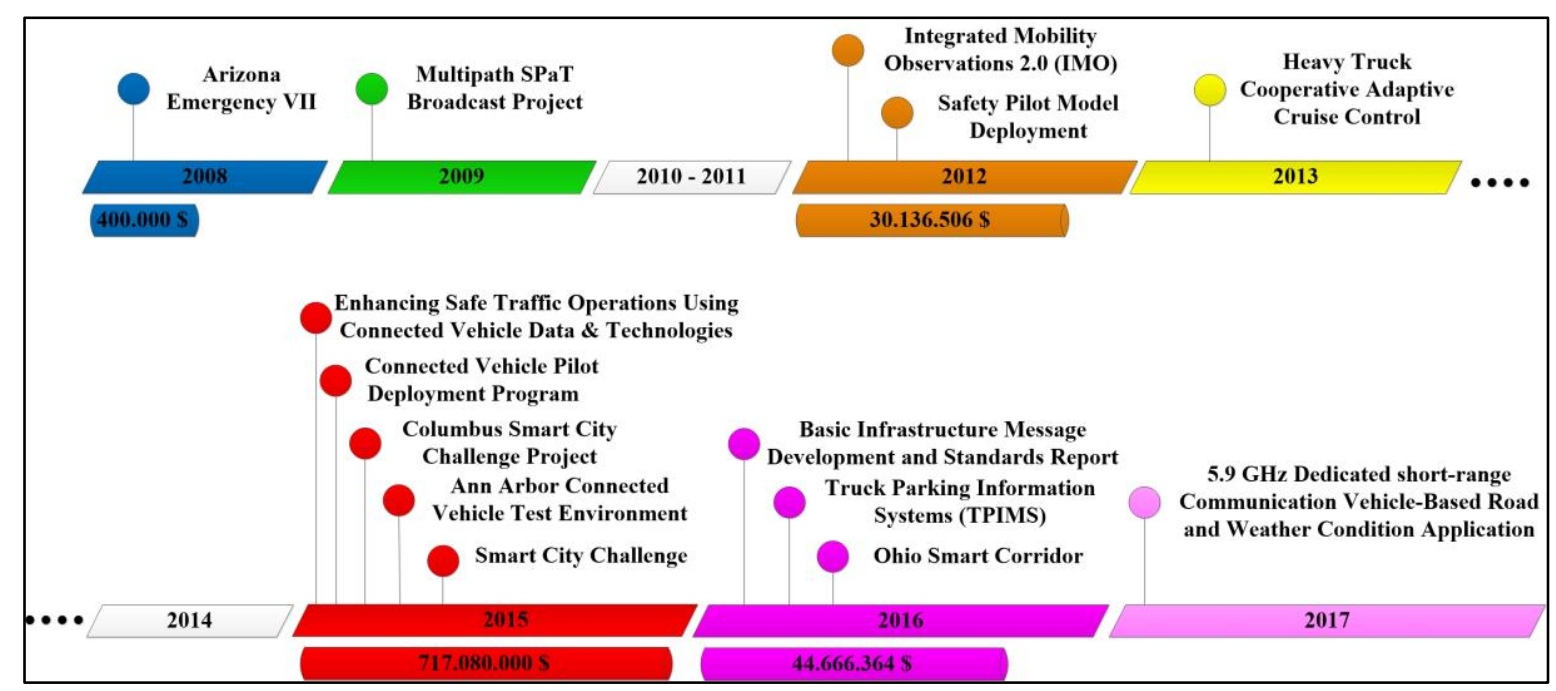

Figure 3: Large-scale deployment projects in USA

Regarding Figure. 2 and Figure. 3, the depicted budgets refer only to projects with available total cost information. Projects with unavailable data are not included.

\section{Conclusions}

The identification of the status of C-ITS deployment projects in Europe and USA demonstrates a large number of activities, devoted to the design and development of C-ITS. Common objective is the integration and wide-scale implementation of C-ITS technologies for the provision and enhancement of road safety, environmental sustainability, as well as efficient mobility of goods and people.

Europe owns a sufficient C-ITS deployment strategy, promoting joint C-ITS deployment activities, which aim to develop and share technical specifications, and to verify interoperability through cross-site testing. Europe's vision on the interoperable deployment of C-ITS is supported by a significant number of C-ITS projects, funded under several programmes, with the scope of creating innovative C-ITS services for all European citizens. USA has proceeded in the development of regulatory and policy rulings, required to foster the growth of $\mathrm{CV}$, in order to tackle big challenges in transportation. The USDOT focuses on coordinating the collaboration amongst various stakeholders to achieve CV deployment and widespread implementation in the real world. Through a series of projects, USDOT supports its first priority, which is to improve roadway safety conditions for American drivers, as well as to exhibit profound effects on VRUs' safety. 
Conducting a comparison between the European and US C-ITS deployment activities, it is observed that Europe, although having an adequate deployment background, is still in initial steps for tackling the technical challenges of C-ITS interoperability. On the other hand, USA has managed to establish clear guidelines, and to define C-ITS deployment under a national architecture framework. The future of C-ITS technologies is already coming into focus for both Europe and USA, leading the way in the development of autonomous mobility.

\section{References-Bibliography}

European Commission (2010). Directive 2010/40/EU of the European Parliament and of the Council of 7 July 2010 on the framework for the deployment of Intelligent Transport Systems in the field of road transport and for interfaces with other modes of transport. Retrieved from: http://eur-lex.europa.eu/LexUriServ/LexUriServ.do?uri=OJ:L:2010:207:0001:0013:EN:PDF.

European Commission (2011). White Paper on transport: Roadmap to a single European transport area-Towards a competitive and resource-efficient transport system. Retrieved from: https://ec.europa.eu/transport/sites/transport/files/themes/strategies/doc/2011_white_paper/wh ite-paper-illustrated-brochure_en.pdf.

Amsterdam Group (2013, June 7). Roadmap between automotive industry and infrastructure organisations on initial deployment of Cooperative ITS in Europe. (Version 1.0). [On-line]. Retrieved from: https://amsterdamgroup.mett.nl/Road+Map/default.aspx.

European Commission. (2016a, Nov. 30). Communication from the Commission to the European Parliament, the Council, the European Economic and Social Committee and the Committee of the Regions-A European strategy on Cooperative Intelligent Transport Systems, a milestone towards cooperative, connected and automated mobility. (COM(2016) 766 final). Retrieved from: https://ec.europa.eu/transport/sites/transport/files/com20160766_en.pdf.

Amsterdam Group. The Amsterdam Group White Papers. Retrived from: https://amsterdamgroup.mett.nl/White+papers/default.aspx.

C-ITS Platform (2016, Jan.). C-ITS Platform-Final report. Retrived from: https://ec.europa.eu/transport/sites/transport/files/themes/its/doc/c-its-platform-final-reportjanuary-2016.pdf.

European Commission (2016b, Apr. 7). A Master Plan for the deployment of Interoperable Cooperative Intelligent Transport Systems in the EU. Retrived from: http://ec.europa.eu/smartregulation/roadmaps/docs/2016_move_040_cooperative_intelligent transport_en.pdf.

European Commission (2016c, Apr. 14-15). Declaration of Amsterdam Cooperation in the field of connected and automated driving. Retrieved from: https://www.regjeringen.no/contentassets/ba7ab6e2a0e14e39baa77f5b76f59d14/2016-04-08declaration-of-amsterdam---final1400661.pdf.

European Commission (2017a, June). C-ITS Platform Phase II-Certificate Policy for Deployment and Operation of European Cooperative Intelligent Transport Systems (C-ITS). (Release 1). Retrived from: https://ec.europa.eu/transport/sites/transport/files/cits_certificate_policy_release_1.pdf. 
U.S. Department of Transportation (2019a). National ITS Architecture. Retrieved from: https://www.its.dot.gov/research_archives/arch/index.htm.

U.S. Department of Transportation (2019b). Turbo Architecture: A Tool for Leveraging The National ITS Architecture. Retrieved from: https://www.fhwa.dot.gov/publications/publicroads/00mayjun/turbo.cfm.

Stančič Z., Appel. P. H. (2009, Nov. 13). EU-U.S. Joint Declaration of Intent on Research Cooperation in Cooperative Systems. Retrieved from: http://itsstandards.info/eu_us_joint_decl_on_coop_systems.pdf.

U.S. Department of Transportation. (2014, Sept. 29). 2015 FHWA Vehicle to Infrastructure Deployment Guidance and Products. Retrieved from: https://www.its.dot.gov/meetings/pdf/V2I_DeploymentGuidanceDraftv9.pdf.

U.S. Department of Transportation (2017a). Connected Vehicle Reference Implementation Architecture. Retrieved from: https://www.its.dot.gov/factsheets/pdf/CVRIA.pdf.

U.S. Department of Transportation (2017b). Architecture Reference for Cooperative and Intelligent Transportation. Retrieved from: https://local.iteris.com/arc-it/.

U.S. Department of Transportation (2017c). RAD-IT. Retrieved from: https://local.iteris.com/arc-it/html/resources/radit.html.

U.S. Department of Transportation (2017d). SET-IT. Retrieved from: https://local.iteris.com/arc-it/html/resources/setit.html.

European Commission (2007). Cooperative systems for road safety "Smart Vehicles on Smart Roads". Retrieved from: https://cordis.europa.eu/project/rcn/80569_en.html.

European Commission (2008). Co-operative networks for intelligent road safety. Retrieved from: https://cordis.europa.eu/project/rcn/79301_en.html.

European Commission (2016d). Co-operative Vehicle-Infrastructure Systems. Retrieved from: https://cordis.europa.eu/project/rcn/79316_en.html.

European Commission (2017b). Advanced telematics for enhancing the SAFEty and comfort of motorcycle RIDERs. Retrieved from: https://cordis.europa.eu/project/rcn/85335_en.html.

European Commission (2017c). euroFOT (European Field Operational Test on Active Safety Functions in vehicles). Retrieved from: https://cordis.europa.eu/project/rcn/87266 en.html.

FOT-NET DATA. SISCOGA. Retrieved from: http://wiki.fot-net.eu/index.php/SISCOGA.

European Commission (2017d). Preparing Secure Vehicle-to-X Communication Systems. Retrieved from: https://cordis.europa.eu/project/rcn/97466_en.html.

European Commission (2017e). Communications for eSafety2. Retrieved from: https://cordis.europa.eu/project/rcn/97474_en.html.

European Commission (2017f). European Field Operational Test on Safe, Intelligent and Sustainable Road Operation. Retrieved from: https://cordis.europa.eu/project/rcn/98318_en.html. 
European Commission (2017g). IPv6 ITS Station Stack for Cooperative Systems FOTs. Retrieved from: https://cordis.europa.eu/project/rcn/98319_en.html.

European Commission (2017h). Europe-Wide Platform for Cooperative Mobility Services. Retrieved from: https://cordis.europa.eu/project/rcn/106007_en.html.

European Commission (2017i). Public procurement of innovation FOR cooperative ITS. Retrieved from: https://cordis.europa.eu/project/rcn/191773_en.html.

European Commission (2014a). Improving the safety and mobility of Vulnerable Road Users through ITS Applications. Retrieved from: https://cordis.europa.eu/project/rcn/186986_en.html.

European Commission (2014b). Cooperative mobility solution for supervised platooning. Retrieved from: http://www.companion-project.eu/.

European Commission (2017j). Harmonised eCall European Pilot-Phase 2. Retrieved from: https://cordis.europa.eu/project/rcn/191758_en.html.

European Commission (2017k). Field Operational Tests of Aftermarket and Nomadic Devices in Vehicles. Retrieved from: https://cordis.europa.eu/project/rcn/87679_en.html.

European Commission (2014c). DRIVE C2XInDRIVing implementation and Evaluation of $\mathrm{C} 2 \mathrm{X}$ communication technology in Europe. Retrieved from: https://cordis.europa.eu/project/rcn/97464_en.html.

European Commission (20171). Cooperative Mobility Systems and Services for Energy Efficiency. Retrieved from: https://cordis.europa.eu/project/rcn/94140_en.html.

European Commission (2017m). interactIVe. Retrieved from: https://www.cordis.europa.eu/project/rcn/93555_en.html.

European Commission (2017n). Open VEhiculaR SEcurE platform. Retrieved from: https://www.cordis.europa.eu/project/rcn/93270_en.html.

European Commission (2017o). Urban Freight Energy Efficiency Pilot. Retrieved from: https://www.cordis.europa.eu/project/rcn/191865_en.html.

European Commission (2017p). Cooperative Systems for Sustainable Mobility and Energy Efficiency. Retrieved from: https://cordis.europa.eu/project/rcn/191745_en.html.

Europen Commission (2017q). Harmonised eCall European Pilot. Retrieved from: https://cordis.europa.eu/project/rcn/191889_en.html.

European Commission (2017r). Cooperative Mobility Pilot on Safety and Sustainability Services for Deployment. Retrieved from: https://cordis.europa.eu/project/rcn/191947_en.html.

European Commission (2017s). COoperative loGISTICS for sustainable mobility of goods. Retrieved from: https://cordis.europa.eu/project/rcn/191843_en.html.

European Commission (2015). SCOOP@F. Retrieved from: https://ec.europa.eu/inea/sites/inea/files/fichenew_2013-fr-92004-s_final.pdf. 
European Commission (2018a). Repsol Security Parking. Retrieved from: https://ec.europa.eu/inea/en/connecting-europe-facility/cef-transport/repsol-security-parking

European Commission (2018b). I_HeERO. Retrieved from: https://ec.europa.eu/inea/en/connecting-europe-facility/cef-transport/iheero

European Commission (2018c). NordicWay. Retrieved from: https://ec.europa.eu/inea/en/connecting-europe-facility/cef-transport/nordicway.

European Commission (2009). CITRUS Coöperatieve ITS for Trucks. Retrieved from: https://www.citrus-project.eu/.

European Commission (2018d). SOLRED C-ITS Monitoring Network (SolC-ITS). Retrieved from: https://ec.europa.eu/inea/en/connecting-europe-facility/cef-transport/solred-c-itsmonitoring-network-solc-its.

European Commission (2018e). InterCor. Retrieved from: https://ec.europa.eu/inea/en/connecting-europe-facility/cef-transport/intercor.

C-ROADS. C-Roads - The Platform of harmonised C-ITS deployment in Europe. Retrieved from: https://www.c-roads.eu/platform.html.

European Commission (2017t). PROactive Safety for PEdestrians and CyclisTs. Retrieved from: https://cordis.europa.eu/project/rcn/193275_en.html

European Commission (2017u). Cooperative ITS for Mobility in European Cities. Retrieved from: https://cordis.europa.eu/project/rcn/196891_en.html.

European Commission (2017v). COoperative ITS DEployment Coordination Support. Retrieved from: https://cordis.europa.eu/project/rcn/194851_en.html.

European Commission (2017w). Advanced measures to reduce cyclists' fatalities and increase comfort in the interaction with motorised vehicles. Retrieved from: https://cordis.europa.eu/project/rcn/193364_en.html.

European Commission (2018f). Accelerating C-ITS Mobility Innovation and depLoyment in Europe." Retrieved from: https://ec.europa.eu/inea/en/horizon-2020/projects/h2020transport/intelligent-transport-systems/c-mobile.

Vermaat P., Hopkin J., van Wees K. A. P. C., Faber F., Deix S., Nitsche P., and Michael. K. (2012, Feb. 2). Deliverable 1 State of the Art report. (Version number 1.0). Retrieved from: http://www.cedr.eu/download/other_public_files/research_programme/eranet_road/call_2011/ mobility/cobra/01_cobra_d1-report-with-overview-of-developments-of-cs-including-legalissues.pdf.

Mitsakis E., Iordanopoulos P., Aifadopoulou G., Tyrinopoulos Y., and Chatziathanasiou M. (2015). Current status and future prospects of Intelligent Transport Systems deployment in South East Europe. Transportation Research Board.

Celtic-Plus Smart Connected World. Project CoMoSeF. Retrieved from: https://www.celticplus.eu/project-comosef/.

Blervaque V. (2016). C-The Difference Beyond Traffic Jams C-ITS urban pilots The Urban Development Network Dialogue 5-Financial investments for urban connected an cooperative 
ITS

systems.

Retrieved

from:

http://ec.europa.eu/regional_policy/sources/conferences/udn_brussels_2016/5.2\%20\%20Vinc ent $\% 20$ Blervaque.pdf.

Cooperative Cars eXtended - CoCarX. Activating mobile traffic channels. Retrieved from: https://amicale-citroen.de/wp-content/uploads/2011/08/CoCarX-Cooperative-Cars-ExtendedResearch-Project.pdf.

FOT-NET DATA. SIMTD. Retrieved from: http://wiki.fot-net.eu/index.php/SIMTD.

European Commission (2018h). Cooperative Sensor Systems and Cooperative Perception Systems for Preventive Road Safety. Retrieved from: https://trimis.ec.europa.eu/programme/cooperative-sensor-systems-and-cooperativeperception-systems-preventive-road-safety.

UR:BAN Urbaner Raum: Benutzergerechte Assistenzsysteme und Netzmanagement. Urban Space: User oriented assistance systems and network management. Retrieved from: http://urban-online.org/en/urban.html.

FOT-NET DATA. SPITS. Retrieved from: http://wiki.fot-net.eu/index.php/SPITS.

FOT-NET DATA. Brabant In-Car II: ParckR. Retrieved from: http://wiki.fotnet.eu/index.php/Brabant_In-Car_II:_ParckR.

Ministry of Infrastructure and the Environment (2017). Optimising Use Programme Working together is key. Retrieved from: https://beterbenutten.nl/assets/upload/files/Optiming\%20Use\%20(May\%202017).pdf.

DITCM Innovations (2017). DITCM Programma. Retrieved from: http://www.ditcm.eu/images/Oktober_2017/DITCM_folder_programma_2017.pdf.

ECo-AT The Austrian contribution to the Cooperative ITS Corridor. Testfeld Telematik. Retrieved from: http://www.eco-at.info/testfeld-telematik-220.html.

ECo-AT The Austrian contribution to the Cooperative ITS Corridor. Cooperative Intelligent Transport Systems (C-ITS). Retrieved from: http://www.eco-at.info/project-description.html.

FOT-NET DATA. SCOREF. Retrieved from: http://wiki.fot-net.eu/index.php/SCOREF.

Department for Transport (2016). The A2/M2 (London to Dover) Connected Vehicle Corridor. Retrieved from: http://www.codecs-project.eu/fileadmin/user_upload/pdfs/Workshop_CITS_Deployment_underway_II/Hanson_InterCor_UK.pdf.

Cooperative ITS Corridor Joint deployment. "Cooperative Traffic Systems-safe and intelligent - Introduction to the corridor: Rotterdam -Frankfurt/M.-Vienna. Retrieved from: http://c-itskorridor.de/?menuId=1\&sp=en.

Saleem F., and Nodes S. (2008). Arizona Emergency VII [E-VII] Program Overview and Focus Areas. Retrieved from: http://www.u.arizona.edu/ heqing/jjs_files/az-overview-Feb08.pdf.

Robinson R., and Dion F.. Multipath SPAT Broadcast Project. Retrieved from: http://www.umtri.umich.edu/our-results/publications/multipath-spat-broadcast-project. 
US Department of Transportation (2018). Safety Pilot Model Deployment. Retrieved from: https://www.nhtsa.gov/sites/nhtsa.dot.gov/files/812171-

safetypilotmodeldeploydeltestcondrtmrep.pdf.

Belzowski B. M., and Cook. S. J.. Integrated Mobile Observations 2.0 Project Final Report. Retrieved from: https://deepblue.lib.umich.edu/bitstream/handle/2027.42/117506/103240.pdf?sequence=1\&is Allowed=y.

Dr. Bevly D., Dr. Murray C., Dr. Lim A., Dr. Turochy R., Dr. Sesek R., Smith S., Apperson G., Woodruff J., Gao S., Gordon M., Smith N., Watts A., Dr. Batterson J., Bishop R., Murray D., Torrey F., Korn A., Dr. Switkes J., and Boyd S. (2015). Heavy Truck Cooperative Adaptive Cruise Control: Evaluation, Testing, and Stakeholder Engagement for Near Term Deployment: Phase One Final Report. Retrieved from: http://eng.auburn.edu/ dmbevly/FHWA_AU_TRUCK_EAR/FHWA_AuburnDATP_Phase1F inalReport.

Li Z. (2016). Enhancing Safe Traffic Operations Using Connected Vehicles Data and Technologies. Retrieved from: http://depts.washington.edu/pactrans/research/projects/enhancing-safe-traffic-operationsusing-connected-vehicles-data-and-technologies-year-4-2015-2016/.

UMTRI. Transportation Research Institute University of Michigan. About Ann Arbor Connected Vehicle Test Environment (AACVTE). Retrieved from: http://www.aacvte.org/getconnected/586-2/.

US Department of Transportation (2018). "Connected Vehicle Pilot Deployment Program." Retrieved from: https://www.its.dot.gov/pilots/technical_assistance_events.htm.

US Department of Transportation (2018). New York City (NYC) DOT Pilot. Retrieved from: https://www.its.dot.gov/pilots/pilots_nycdot.htm.

US Department of Transportation (2018). Tampa (THEA) Pilot. Retrieved from: https://www.its.dot.gov/pilots/pilots thea.htm.

US Department of Transportation (2018). Wyoming (WY) DOT Pilot. Retrieved from: https://www.its.dot.gov/pilots/pilots_wydot.htm.

US Department of Transportation (2018). Smart City Challenge: Lessons for Building Cities of the Future. Retrieved from: https://www.transportation.gov/smartcity.

US Department of Transportation (2018). Smart City Challenge Winner. Retrieved from: https://www.transportation.gov/smartcity/winner.

Mid America Association of State Transportation Officials (2016). The MAASTO TPIMS Project. Retrieved from: https://trucksparkhere.com/wpcontent/uploads/2016/08/TheMAASTO_TPIMSProject_FactSheet_2016_08_11.pdf.

Smart Mobility Corridor. Smart Mobility. Retrieved from: https://www.33smartcorridor.com/mobility.

US Department of Transportation (2018). 5.9 GHz Dedicated short-range communication Vehicle-based Road and Weather Condition Application. Retrieved from: 
https://www.its.dot.gov/presentations/Road_Weather2014/6A\%20Garrett_CTS_PFS_DSRC $\underline{\text { RdWx_20140813.pdf. }}$. 